\title{
Concurrent validity of the pressure biofeedback unit and surface electromyography in measuring transversus abdominis muscle activity in patients with chronic nonspecific low back pain
}

\author{
Validade concorrente da unidade de biofeedback pressórico e eletromiografia \\ de superfície na mensuração da atividade muscular do transverso abdominal em \\ pacientes com dor lombar crônica inespecífica
}

Pedro O. P. Lima', Rodrigo R. Oliveira', Alberto G. Moura Filho², Maria C. F. Raposo ${ }^{3}$, Leonardo O. P. Costa4, Glória E. C. Laurentino²

\begin{abstract}
Background: The Pressure biofeedback unit (PBU) is an assessment tool used in clinical practice and research aimed to indirectly analyze the transversus abdominis ( $\operatorname{Tr} A)$ muscle activity. The concurrent validity of the PBU in a clinically relevant sample is still unclear. Objective: The purpose of this study was to evaluate the concurrent validity and diagnostic accuracy of the PBU in measuring TrA muscle activity in patients with chronic nonspecific low back pain. Method: This study was performed using a validation, cross-sectional design. Fifty patients with chronic nonspecific low back pain were recruited for this study. To test the concurrent validity both PBU measures (index test) and superficial electromyographic measures (reference-standard test) were compared and collected by a physical therapist in a series of voluntary contraction maneuvers of TrA muscle. Results: Participants were on average 22 years old, weighed 63.7 kilos, 1.70 meters height and mean low back pain duration was 1.9 years. It was observed a weak and non-significant Phi coefficient $(r=0.2, p<0.20)$. With regards to diagnostic accuracy tests, our results suggest a low sensitivity $(60 \%)$ and specificity $(60 \%)$ of the PBU. The positive predictive value was high (0.8) and negative predictive value was low (0.2). Conclusions: Concurrent validity of the PBU in measuring TrA muscle activity in patients with chronic nonspecific low back pain is poor given the low correlation and diagnostic accuracy with superficial EMG.
\end{abstract}

Keywords: pressure biofeedback unit; low back pain; physical therapy.

\section{Resumo}

Contextualização: A Unidade de Biofeedback Pressórico (UBP) é uma ferramenta de avaliação usada na prática clínica e pesquisa científica para analisar indiretamente a atividade muscular do transverso abdominal ( $\operatorname{Tr} A)$. A validade concorrente da UBP em uma amostra clinicamente relevante ainda não está esclarecida. Objetivo: Avaliar a validade concorrente e acurácia diagnóstica da UBP em mensurar a atividade muscular do TrA em pacientes com dor lombar crônica inespecífica. Método: Este estudo foi realizado usando um delineamento de validação. Cinquenta pacientes com dor lombar crônica inespecífica foram recrutados. Para testar a validade concorrente, ambas as medidas pressóricas (teste índice) e eletromiográficas superficiais (teste padrão de referência) foram comparadas e coletadas por um fisioterapeuta a partir de uma manobra de contração voluntária do músculo TrA. Resultados: Os participantes tinham em média 22 anos, 63,7 kg, 1,70 m de altura, e a duração média de dor lombar era de 1,9 ano. Observou-se um coeficiente Phi fraco e não significativo $(r=0,2 ; p<0,20)$. Com relação aos testes de acurácia diagnóstica, os resultados sugerem uma baixa sensibilidade (60\%) e especificidade (60\%) da UBP. O valor preditivo positivo foi elevado $(0,8)$, e o valor preditivo negativo foi baixo $(0,2)$. Conclusões: A validade concorrente da UBP em mensurar a atividade muscular do TrA em pacientes com dor lombar crônica inespecífica é pobre, considerando a baixa correlação e acurácia diagnóstica com a EMG de superfície.

Palavras-chave: biofeedback pressórico; dor lombar; fisioterapia.

\section{Received: 11/06/2011 - Revised: 03/26/2012 - Accepted: 05/18/2012}

\footnotetext{
Physical Therapy Department, Universidade Federal do Ceará (UFC), Fortaleza, CE, Brazil

${ }^{2}$ Physical Therapy Department, Universidade Federal do Pernambuco (UFPE), Recife (PE), Brazil

${ }^{3}$ Department of Statistics, UFPE, Brazil

${ }^{4}$ Master's Program in Physical Therapy, Universidade da Cidade de São Paulo (UNICID), São Paulo, SP, Brazil

Correspondence to: Pedro O. P. Lima, Laboratório de Análise do Movimento Humano, Rua Alexandre Baraúna, 949, CEP 60430-110, Fortaleza, CE, Brasil, e-mail: pedrolima@ufc.br
} 


\section{Introduction $: \therefore$}

Low back pain is considered as a major public health problem and is associated with high socioeconomic costs, work absenteeism and disability ${ }^{1,2}$. Usually, acute low back pain presents a favorable prognosis with most patients returning to their usual activities between 4 to 8 weeks, but recurrence is common ${ }^{3}$. Approximately $10-40 \%$ of acute low back pain patients become chronic and most of them (85\%) are classified as nonspecific. Patients who develop chronic nonspecific low back pain (i.e., persistent pain and disability for more than three months) are responsible for more than $80 \%$ of health care that are spent for spinal problems ${ }^{4,5}$. The European Guidelines for the Management of Low Back Pain recommends motor control exercises and spinal manipulative therapy as possible choices for the clinical management of chronic nonspecific low back pain ${ }^{6-8}$.

A delay in the onset of activation of the transversus abdominis (TrA) muscle has been observed in patients with recurrent low back pain compared to asymptomatic controls ${ }^{9,10}$. In addition, longitudinal studies have shown that specific exercise for TrA muscle is effective in reducing low back pain recurrences ${ }^{11,12}$. In general, the gold-standard method used for measuring the activity of the deep abdominal wall muscles is fine-wire electromyography. However, some factors such as high cost, pain, discomfort and risk of infection make the use of this method less likely to be used in clinical practice. Ultrasound imaging and palpation tests are also used for measuring activity these muscles, however recent evidence have suggested that reproducibility studies are not acceptable for these evaluation tools ${ }^{13,14}$. Several studies have used surface electromyography in measuring of TrA muscle activity $^{15-18}$. Surface EMG has reasonable measurement properties such as validity (cross-correlation of 0.69) and reproducibility (Intraclass Correlation Coefficient of 0.90) during the drawingin maneuver, but high cost hinders the widespread its use in clinical practice ${ }^{19}$.

Other valid and reliable instruments that are noninvasive and low cost could be useful to measure the TrA muscle activity favoring the clinical management of patients with chronic nonspecific low back pain ${ }^{20,21}$. Accordingly, the pressure biofeedback unit (PBU) could be considered as an alternate approach to indirectly measure TrA muscle activity ${ }^{22-24}$. The PBU is a simple pressure transducer consisting of a three-chamber air-filled pressure bag, a catheter and a sphygmomanometer gauge ${ }^{24,25}$. The pressure bag has $16.7 \times 24 \mathrm{~cm}$ in size and made from non-elastic material. The sphygmomanometer scale ranges from $0 \mathrm{mmHg}$ to $200 \mathrm{mmHg}$, with $2 \mathrm{mmHg}$ intervals on the scale. Movement or change in position causes volume changes in the pressure bag, which is registered by this device.
It is necessary that pressure measures of the abdominal muscle activity have a minimum level of validity to be useful. Validity is the degree to which the measure represents the phenomenon of interest, and refers to how much an instrument measures what it would be supposed to measure ${ }^{26}$. Thus, when an instrument undergoes a validation process, in fact is not the instrument itself that is being validated, but the purpose for which the instrument is being used ${ }^{27}$. There are five types of validity described in the literature: face, content, criterion, construct and concurrent validity. Concurrent validity refers to the extent to which scores on a particular instrument relate to a reference standard (i.e., not a gold standard) and is consistent with theoretically derived hypotheses concerning the concepts that are being measured ${ }^{27-30}$.

Clinimetric properties of the PBU in measuring TrA muscle activity have been discussed in many studies ${ }^{22,25,31-34}$, but most of them sampled solely healthy individuals ${ }^{22,25,32,33}$, and two ${ }^{31,34}$ recruited subjects with history of low back pain. Of the six studies, only on $\mathrm{e}^{31}$ investigated the validity of this instrument and, despite the authors have concluded that the PBU provides valid measures, their findings are not conclusive due to the suboptimal methodological quality, such as small sample size $(\mathrm{n}=15)$ and use of different motor tasks to assess TrA muscle activity ${ }^{31}$. A recent systematic review from our research group has summarized main methodological limitations of studies on measurement properties of the $\mathrm{PBU}^{35}$. Furthermore, a recently low risk of bias study on the reproducibility of the PBU was conducted and observed ICCs of 0.74 and 0.76 for intra and inter-examiner reproducibility, respectively ${ }^{36}$. Scientific findings are more accepted when different studies investigate the effects of an intervention or test, obtain similar conclusions ${ }^{37}$. Thus, clinimetric properties of the measures should be studied and presented for that the quality of the results can be evaluated.

Therefore, considering the importance of the use of validated measures that can support clinical practice and considering the scarcity of studies concerning the validation of the PBU in a clinically relevant sample, the purpose of this study was to evaluate the concurrent validity and diagnostic accuracy of the PBU in measuring TrA muscle activity in patients with chronic nonspecific low back pain.

\section{Method : $:$}

This study used a validation, cross-sectional design ${ }^{38}$, and was carried out at the Laboratory of Kinesiology and Functional Assessment of the Department of Physical Therapy 
of the Universidade Federal do Pernambuco (UFPE), Recife, PE, Brazil in 2009.

The sample was selected from students of the UFPE with chronic nonspecific low back pain. This study was approved by the Institutional Research Ethics Committee (Agamenon Magalhães Hospital, Recife, PE, Brazil) (\#00490236000-09). All participants signed an informed consent form. The required sample size was estimated based upon the recommendations of specific guidelines on clinimetric properties that suggest a sample of at least 50 individuals for validation studies ${ }^{28}$.

We included participants with chronic nonspecific low back pain (i.e., low back pain of at least three months duration and without a specific cause) $)^{39}$. We excluded participants who had acute low back pain (i.e., an episode of low back pain of less than 6 weeks), those who were pregnant, who had previous abdominal wall or spinal surgery, with a body mass index (BMI) of 25 or over, were menstruating during the tests and those with suspected or confirmed serious pathologies (i.e, nerve root compromise; fractures; cancer; infectious diseases of the spine; cauda equina syndrome and widespread neurological disorders).

All participants received basic information about the anatomy, biomechanics and functions of the TrA muscle, as well as they received training of the TrA muscle contraction, which has been described in detail in the literature ${ }^{22,25,33,34,40}$. All subjects were previously instructed to fast for 2 hours prior to testing (including water), empty the bladder immediately before the tests and to not perform abdominal exercises two days prior to the tests ${ }^{22}$. For both tests, participants and examiners have adopted the same positioning, environmental and temporal conditions to avoid external influences or internal errors during data collection. Participants were positioned in a prone position on a hard surface, with the lower limbs positioned with the feet off the plinth and with the arms beside the trunk.

To test the concurrent validity of PBU, surface electromyography (EMG) was considered as the reference-standard test, based on the findings of previous studies on the topic ${ }^{19,41,42}$ and considering the questions of the ethics committees in Brazil (our ethics committee did not allowed us to use fine-wire EMG). For all patients, we firstly tested the TrA muscles using the surface EMG (Miotec ${ }^{\circledR}$ Miotool 400) under the conditions described below. Before placing the electrodes, detection surfaces were properly cleaned, exfoliated and, when necessary shaving was performed following the recommendations of ISEK (International Society of Electrophysiology and Kinesiology) and SENIAM (Surface Electromyography for Non Invasive Assessment of Muscles) $)^{43}$ to allow a low impedance between the skin and the electrodes. The bipolar surface electrodes
$\left(\mathrm{Ag} / \mathrm{AgCl}\right.$ - Meditrace $\left.{ }^{\circledR}\right)$ were placed with a distance of $20 \mathrm{~mm}$ between their centers, and placed at right side in the area corresponding to the TrA/OI (transversus abdominis/internal oblique) muscles, located $2 \mathrm{~cm}$ from the anterior superior iliac spine, following the instructions established by Hodges, Gandevia and Richardson ${ }^{41}$ and adapted by Chanthapetch et $\mathrm{al}^{42}$. The reference electrode was placed in the right lateral epicondyle. Participants were positioned on supine position with knees flexed at $90^{\circ}$.

We firstly recorded 30 seconds at rest to detect the parameters of electromyographic silence (basal tonus). Then, it was performed the protocol of maximal voluntary isometric contraction (MVIC) in agreement with the standards of SENIAM ${ }^{43}$ three contractions of 5 seconds with intervals of 3 seconds between each contraction, with three repetitions. Each participant had one minute of rest between repetitions. To finish the electromyographic collection was requested a TrA muscle contraction maintained for 10 seconds. Overall, there were five electromyographic records from each subject. The signs of electrical activity of TrA muscle were collected and transmitted to a monitor that was connected to the EMG equipment. EMG data were sampled at $1000 \mathrm{~Hz}$ over a bandwidth of 20-450 Hz (bandpass filter). The raw EMG signals generated were analyzed using the root mean square (RMS). EMG data were normalized by the percentage of MVIC and significant electromyographic activity (positive result - success) was defined as an activity at least 10\% of the MVIC 44,45

After obtaining EMG recordings and respecting an interval of 15 minutes, we measured the TrA muscle activity from the PBU. Participants were positioned on prone position and the inflatable bag was placed between the anterior superior iliac spine and navel. Before starting the contraction, the bag was inflated to a pressure of $70 \mathrm{mmHg}$ with the valve closed and participants were instructed to breathe deeply using mainly abdominal wall, then the inflatable bag was adjusted to $70 \mathrm{mmHg}$ again. Patients were requested to perform three TrA muscle contractions with following verbal commands standardized by examiner: "Draw in your abdomen without moving the spine or pelvis" and maintain these contractions for ten seconds ${ }^{22}$.The examiner have checked by palpation if the participants were moving (in contrast to the instructions) the spine or pelvis. According to the manufacturer of PBU (Stabilizer ${ }^{\circledR}$, Chattanooga Group Inc., Hixson, TN, USA), the ability to contract the TrA muscle results in a pressure reduction from 4 to $10 \mathrm{mmHg}$, which is recorded by pressure gauge of $\mathrm{PBU}^{24}$. Thus, based on this information and previous studies on the topic $c^{24,35,36}$, a pressure reduction of at least $4 \mathrm{mmHg}$ during 10 seconds from an average of three trials was defined as a positive result (success) (Figure 1). To ensure 
that changes in pressure were not due to a leak in the pressure biofeedback unit cushion, the PBU was calibrated according to the recommendations established by von Garnier ${ }^{34}$.

A trained and experienced examiner performed both measurements of surface EMG and PBU. All information was recorded using a digital evaluation form provided by specific software $\left(\right.$ Miograph $\left.{ }^{\circledR}\right)$. Pain intensity was measured by the $\mathrm{Nu}-$ merical Pain Rating Scale and disability was measured by the Roland Morris Disability Questionnaire, both cross-culturally adapted and clinimetrically tested for Brazilian-Portuguese speakers $^{46-48}$.

The sample characteristics are presented using descriptive statistics ${ }^{49}$. To describe the validity, we used the Phi (f) Coefficient, whose values range from -1 to 1 and if it lower than 0.5 can be classified as weak, values between 0.5 and 0.7 are classified as moderate and over 0.7 are classified as strong correlation $^{50,51}$. The relationship between the TrA muscle contraction maintained for 10 seconds measured by the surface EMG (\%MVIC) and the scores of pressure reduction measured by the PBU (mmHg) was the specific hypothesis formulated to analyze the concurrent validity. We hypothesized that the PBU (index test) would have a moderate and positive correlation with the surface EMG (reference-standard test) ${ }^{28,52}$. Furthermore, we calculated the values of diagnostic accuracy tests, such as sensitivity, specificity, positive predictive value (PPV) and negative predictive value (NPV). Data were analyzed with SPSS (Statistical Package for Social Sciences) version 15.0, considering the significance level of $\mathrm{p}<0.05$ in all calculations.

\section{Results $: \because$.}

The sample characteristics are presented in Table 1. Of the 50 participants, 38 (76\%) were women and were on average 22 years old, weighed 63.7 kilos and had an average height of 1.70 meters. The mean low back pain duration was 1.9 years. The mean low back pain intensity measured by the Pain Intensity Numerical Rating Scale was 5.1 points and the mean disability measured by the Roland Morris Disability Questionnaire was 9.1 points.

The measures performed from the surface EMG obtained mean MVIC of 127.1 (95.5) $\mu \mathrm{V}$, representing 100\% MVIC. The records at rest had a mean of $2.3(1.9) \mu \mathrm{V}$, representing $2.9 \%$ MVIC. The contraction maintained for 10 seconds was 29.6 (21.8) $\mu \mathrm{V}$ on average, representing 24.4\%MVIC. The measures performed from the PBU obtained mean pressure values of -4.1 (2.4) mmHg (Table 2).
According to predetermined criteria to characterize the results as positive (success), 31 (62\%) patients received similar ratings by the two assessment instruments, but 19 (38\%) were classified as false-positive (8\%) and false-negative (30\%), which shows a weak and non-significant correlation of Phi $=0.2(\mathrm{p}<0.20)$ between the ratings of the PBU and the surface EMG (Table 3).

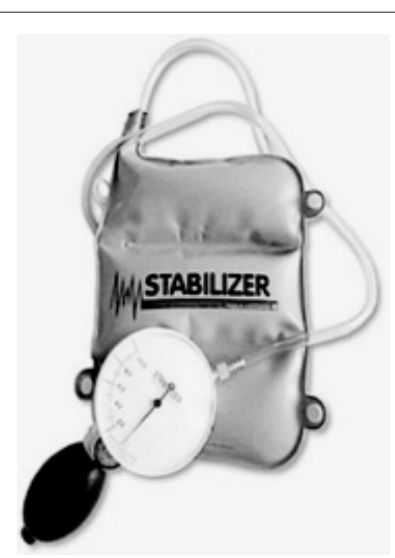

Figure 1. Pressure Biofeedback Unit (Stabilizer $\left.{ }^{\circledR}\right)$.

Table 1. Sample characteristics.

\begin{tabular}{llc}
\hline Variables & & Mean (SD) \\
\hline \multirow{2}{*}{ Gender $(\mathrm{n}, \%)$} & Female & $38(76 \%)$ \\
\cline { 2 - 3 } & Male & $12(24 \%)$ \\
\hline Age (years) & $22.0(2.3)$ \\
\hline Low back pain duration (years) & $1.9(3.4)$ \\
\hline Weight (kg) & $62.7(12)$ \\
\hline Height (m) & $1.7(0.1)$ \\
\hline Pain Intensity Numerical Rating Scale (0-10) & $5.1(1.8)$ \\
\hline Roland Morris Disability Questionnaire (0-24) & $9.1(5.9)$ \\
\hline
\end{tabular}

Table 2. Description of the pressure measures and electromyographic measures during the TrA muscle activity.

\begin{tabular}{lc}
\hline Variables & Mean (SD) \\
\hline Pressure Measures & \\
\hline $\mathrm{PBU}^{\star}(\mathrm{mmHg})$ & $-4.1(2.4)$ \\
\hline Electromyographic Measures & \\
\hline $\mathrm{MVIC} \mathrm{C}^{* \star}(\mu \mathrm{V})$ & $127.1(95.5)$ \\
\hline $\mathrm{MVIC}(\%)$ & 100 \\
\hline Rest $(\mu \mathrm{V})$ & $2.3(1.9)$ \\
\hline Rest $(\%)$ & 2.9 \\
\hline Contraction maintained for 10 seconds $(\mu \mathrm{V})$ & $29.6(21.8)$ \\
\hline Contraction maintained for 10 seconds $(\%)$ & 24.4 \\
\hline
\end{tabular}

*PBU: pressure biofeedback unit; **MVIC: maximal voluntary isometric contraction.

Table 3. 2x2 Table between the PBU ratings and the surface EMG ratings.

\begin{tabular}{lcccc}
\hline & \multicolumn{3}{c}{ SEMG $^{\star \star}$ (reference-standard test) } \\
\cline { 2 - 5 } & & Positive & Negative & Total \\
\hline PBU $^{\star}$ & Positive & $25(50 \%)$ & $4(8 \%)$ & $29(58 \%)$ \\
\cline { 2 - 5 } (index test) & Negative & $15(30 \%)$ & $6(12 \%)$ & $21(42 \%)$ \\
\hline & Total & $40(80 \%)$ & $10(20 \%)$ & $50(100 \%)^{\star \star \star}$ \\
\hline
\end{tabular}

${ }^{*}$ PBU: pressure biofeedback unit; ${ }^{* \star}$ SEMG: surface electromyography; ${ }^{* \star *}$ Phi (f) Coefficient (Phi=0.2, p<0.20). 
Regarding to the diagnostic tests, the results showed low sensitivity (60\%), low specificity (60\%), a high PPV (0.8) and a low NPV (0.2) of the PBU.

\section{Discussion $: \therefore$.}

Our study showed a poor concurrent validity of the PBU in measuring TrA muscle activity during voluntary contraction maneuver in patients with nonspecific chronic low back pain. The usefulness of a measure in research or in clinical practice depends on how much we can rely on the accuracy of the data as indicators of the behavior or the phenomenon assessed. Ideally, any measurement should be practical, easy to obtain and able to produce reliable and valid data, since no consistent measures produce unreliable results, leading to erroneous conclusions ${ }^{53}$.

With regards to the correlation between the ratings of the PBU and the surface EMG, the high disagreement of $38 \%$ showed that the pressure data are not statistically correlated to the EMG data $(\mathrm{Phi}=0.2, \mathrm{p}<0.20)^{50}$. Similar results were found by Hodges, Richardson and Jull ${ }^{54}$, who preliminarily found a non-significant correlation between the absolute estimates of the PBU and fine-wire EMG ( $\mathrm{r}=0.48, \mathrm{p}<0.07)$, but subsequently showed that the same data, when converted into an ordinal scale to classify the two measures had high probability of being correlated (Fisher's exact test, $\mathrm{p}<0.006$ ). Methodological differences can be used as a possible explanation for these conflicting results, since in the study of Hodges, Richardson and Jull ${ }^{54}$, the PBU was used to evaluate the presence of TrA muscle activity and the EMG was used to evaluate the latency period between the onset of contraction of the TrA and anterior deltoid muscles (i.e., the instruments evaluated distinct phenomena). In this study, the two instruments (PBU and surface EMG) were used to evaluate the same phenomenon (i.e., presence of TrA muscle activity).

The scarcity of studies investigating the validity of the PBU makes it harder to perform a detailed analysis of our results. Besides the study of Hodges, Richardson and Jull ${ }^{31}$ other study conducted by Costa et al. ${ }^{22}$ tried to estimate the validity of the PBU with a palpation test, and showed a positive and significant correlation between the two tests $(\mathrm{r}=0.99, \mathrm{p}<0.01)$. However, it is observed that their study compared two clinical tests and did not take into account any laboratory finding, and its methodological approach are questioned by Richardson et al. ${ }^{55}$ and Falla et al. ${ }^{56}$ who found a correlation of $0.56(\mathrm{p}<0.001)$ between PBU and EMG data (contact electrodes attached to a suction catheter), but this study was conducted in individuals with chronic nonspecific neck pain, unlike our sample of chronic low back pain participants.

The possibility of existence of the phenomenon of cross-talk would be a likely explanation for the weak correlation observed between the instruments, however the SENIAM ${ }^{43}$ assumes that the placement of the surface electrodes could collect the electromyographic signals from the TrA and OI muscles. Furthermore, the validity of an assessment instrument is restricted by the reliability of test ${ }^{27}$. This point was not clear in the literature ${ }^{35}$, but a recently published study ${ }^{36}$ about the PBU shows strong evidences of the excellent reproducibility of test. This study was conducted with an adequate sample size, clinically relevant participants and procedures for data collection rigorously executed. Results indicated an $\mathrm{ICC}_{2,1}$ of 0.74 and 0.76 for the intra and inter-examiner reproducibility, respectively. The intra and inter-examiner agreement were within the limits of agreement (LOA) on 95\% of occasions. Therefore, the reproducibility of PBU in measuring TrA muscle activity in patients with chronic nonspecific low back pain can be considered as excellent.

Among many factors that can affect the accuracy of an outcome measure, the lack of standardization is often referred to as an important source of error. In this sense, the definition of certain criteria is essential for a critical assessment as the best evidence available when different studies investigating the effects of a test ${ }^{27,37,38}$. One finding during the development of this study was the benchmark for defining what would be considered "positive result" and "negative result" of the PBU. The criterion of pressure reduction cannot be not considered as biased, because the criterion adopted (at least $4 \mathrm{mmHg}$ ) is the most cited in the literature ${ }^{22,32,33,35,36,57,58}$ and recommended by the equipment manufacturer ${ }^{24}$. The point is that there are no available studies with a ROC (Receiver Operating Characteristics) curve analysis to determine the score-by-score results of the PBU compared to the gold-standard tool. The study conducted by Hodges, Richardson and Jull ${ }^{54}$ is the one that could have clarified this issue, but this statistical method was not performed. Therefore, despite to be a consolidated criterion and repeated by most researchers on the topic and by the manufacturer, this can only be confirmed with a ROC curve analysis ${ }^{27,38,59,60}$. We suggest a future study with primary aim to calculate the ROC curve, unlike the objective of this study.

A limitation during the data collection was the order of the tests was not random. This brings into question whether the results on the PBU test were influenced by the fact the participants were warmed-up, or participants being habituated to the task. Moreover, a fact that may explain the findings of this study is the possibility of the two instruments assess different aspects and the relationship between muscle activity 
and movement is not direct. Although these tests have evaluated the same task (voluntary contraction of TrA muscle), the surface EMG is able to assess amount of muscle activation (and not amount of force or movement) and the PBU is able to evaluate the depression of abdominal wall (which is the ability to generate movement by TrA muscle) indirectly by measuring the pressure reduction recorded by the device. Therefore, a muscle that is more active in the electromyography signal will not necessarily generate more movement. This may happened due to muscle weakness ${ }^{61-63}$.

Regarding to the diagnostic tests, the results showed a low sensitivity (60\%) with small ability of the PBU detect TrA muscle activity when it is present, also showed a low specificity (60\%) with small ability of the PBU to rule outTrA muscle activity when it is absent. Based on these results we can infer that the pressure measures were not sensitive to discriminate the presence of TrA muscle activity and were not specific to identify the absence of the same muscle activity, making questionable the usefulness of the PBU to assess TrA muscle activity in patients with chronic nonspecific low back pain ${ }^{60,64}$. With regards to diagnostic tests, the high PPV (0.8) found, ensures that if result of the PBU is positive, the chance to be a real TrA muscle activity is $80 \%$. While the low NPV (0.2) does not assume that the negative tests of the PBU represent absence of $\operatorname{TrA}$ muscle activity, since if results of the PBU are negative, the chance that there is no TrA muscle activity is only $20 \%$.

Therefore, based on the results observed and the literature, it is emphasized that there was no evidence sufficient to support the concurrent validity of the PBU in measuring TrA muscle activity in patients with chronic nonspecific low back pain.

\section{Acknowledgements : :}

The authors would like to thank CAPES (Coordenação de Aperfeiçoamento de Pessoal de Nível Superior), Brasilia, DF, Brazil - Ministério da Educação and FAPESP (Fundação de Amparo a Pesquisa do Estado de São Paulo), São Paulo, SP, BRazil.

\section{References $: \because$.}

1. Chou R, Qaseem A, Snow V, Casey D, Cross JT Jr, Shekelle P, et al. Diagnosis and treatment of Iow back pain: a joint clinical practice guideline from the American College of Physicians and the American Pain Society. Ann Intern Med. 2007;147(7):478-91.

2. Chou R, Huffman LH; American Pain Society; American College of Physicians. Nonpharmacologic therapies for acute and chronic low back pain: a review of the evidence for an American Pain Society/American College of Physicians clinical practice guideline. Ann Intern Med. 2007;147(7):492-504

3. Swinkels-Meewisse EJ, Swinkels RA, Verbeek AL, Vlaeyen JW, Oostendorp RA. Psychometric properties of the Tampa Scale for kinesiophobia and the fear-avoidance beliefs questionnaire in acute low back pain. Man Ther. 2003;8(1):29-36

4. Ferreira ML, Ferreira PH, Latimer J, Herbert RD, Hodges PW, Jennings MD, et al. Comparison of general exercise, motor control exercise and spinal manipulative therapy for chronic low back pain: A randomized trial. Pain. 2007;131(1-2):31-7.

5. Macedo LG, Maher CG, Latimer J, McAuley JH. Motor control exercise for persistent, nonspecific low back pain: a systematic review. Phys Ther. 2009;89(1):9-25

6. Ferreira ML, Ferreira PH, Latimer J, Herbert R, Maher CG. Does spinal manipulative therapy help people with chronic low back pain? Aust J Physiother. 2002;48(4):277-84.

7. Macedo LG, Latimer J, Maher CG, Hodges PW, Nicholas M, Tonkin L, et al. Motor control or graded activity exercises for chronic low back pain? A randomised controlled trial. BMC Musculoskelet Disord. 2008;9:65.

8. Airaksinen O, Brox JI, Cedraschi C, Hildebrandt J, Klaber-Moffett J, Kovacs F, et al. Chapter 4. European guidelines for the management of chronic nonspecific low back pain. Eur Spine J. 2006;15 Suppl 2:S192-300.

9. Hodges PW, Richardson CA. Altered trunk muscle recruitment in people with low back pain with upper limb movement at different speeds. Arch Phys Med Rehabil. 1999;80(9):1005-12.

10. Hodges PW, Richardson CA. Delayed postural contraction of transversus abdominis in low back pain associated with movement of the lower limb. J Spinal Disord. 1998;11(1):46-56.

11. Tsao H, Galea MP, Hodges PW. Reorganization of the motor cortex is associated with postural control deficits in recurrent low back pain. Brain. 2008;131(Pt 8):2161-71

12. Hides JA, Jull GA, Richardson CA. Long-term effects of specific stabilizing exercises for firstepisode low back pain. Spine (Phila Pa 1976). 2001;26(11):E243-8.
13. Sedaghat N, Latimer J, Maher C, Wisbey-Roth T. The reproducibility of a clinical grading system of motor control in patients with low back pain. J Manipulative Physiol Ther. 2007;30(7):501-8.

14. Costa LO, Maher CG, Latimer J, Smeets RJ. Reproducibility of rehabilitative ultrasound imaging for the measurement of abdominal muscle activity: a systematic review. Phys Ther 2009;89(8):756-69.

15. Kane K, Barden J. Contributions of trunk muscles to anticipatory postural control in children with and without developmental coordination disorder. Hum Mov Sci. 2011. [Epub ahead of print].

16. Sapsford RR, Hodges PW, Richardson CA, Cooper DH, Markwell SJ, Jull GA. Co-activation of the abdominal and pelvic floor muscles during voluntary exercises. Neurourol Urodyn. 2001;20(1):31-42.

17. Sjödahl J, Kvist J, Gutke A, Oberg B. The postural response of the pelvic floor muscles during limb movements: a methodological electromyography study in parous women without lumbopelvic pain. Clin Biomech (Bristol, Avon). 2009;24(2):183-9

18. Stüpp L, Resende AP, Petricelli CD, Nakamura MU, Alexandre SM, Zanetti MR. Pelvic floor muscle and transversus abdominis activation in abdominal hypopressive technique through surface electromyography. Neurourol Urodyn. 2011;30(8):1518-21.

19. Marshall P, Murphy B. The validity and reliability of surface EMG to assess the neuromuscular response of the abdominal muscles to rapid limb movement. J Electromyogr Kinesiol. 2003;13(5):477-89.

20. Critchley DJ, Coutts FJ. Abdominal muscle function in chronic low-back pain patients: measurements with real-time ultrasound scanning. Physiotherapy. 2002;88(6):322-32.

21. McMeeken JM, Beith ID, Newham DJ, Milligan P, Critchley DJ. The relationship between EMG and change in thickness of transversus abdominis. Clin Biomech (Bristol, Avon). 2004;19(4):337-42.

22. Costa LOP, Costa LCM, Cançado RL, Oliveira WM, Ferreira PH. Confiabilidade do teste palpatório e da unidade de biofeedback pressórico na ativação do músculo transverso abdominal em indivíduos normais. Acta Fisiátrica. 2004;11(3):101-5.

23. Hodges PW, Pengel LH, Herbert RD, Gandevia SC. Measurement of muscle contraction with ultrasound imaging. Muscle Nerve. 2003;27(6):682-92.

24. Chattanooga G. Stabilizer pressure bio-feedback. Operating instructions. Hixson: Chattanooga Group Inc.; 2005.

25. Storheim K, Bø K, Pederstad 0, Jahnsen R. Intra-tester reproducibility of pressure biofeedback in measurement of transversus abdominis function. Physiother Res Int. 2002;7(4):239-49. 
26. Fletcher RH, Fletcher SW. Epidemiologia Clínica: elementos essenciais. $4^{\text {th }}$ ed. Porto Alegre: Artmed; 2006.

27. Portney LG, Watkins MP. Foundations of clinical research: applications to practice. $3^{\text {rd }}$ ed. Upper Saddle River: Prentice Hall; 2008.

28. Terwee CB, Bot SD, de Boer MR, van der Windt DA, Knol DL, Dekker J, et al. Quality criteria were proposed for measurement properties of health status questionnaires. J Clin Epidemiol. 2007;60(1):34-42

29. Johnston MVK, Keith RA, Hinderer SR. Measurement standards for interdisciplinary medical rehabilitation. Arch Phys Med Rehabil. 1992;73(12-S):S3-23.

30. Armitage P, Colton T. Encyclopedia of biostatistics. $1^{\text {st }}$ ed. Boston: John Wiley \& Sons Ltd; 1998.

31. Hodges PW, Richardson CA. Inefficient muscular stabilization of the lumbar spine associated with low back pain. A motor control evaluation of transversus abdominis. Spine (Phila Pa 1976). 1996;21(22):2640-50

32. Costa LOP, Costa Lda C, Cancado RL, Oliveira WdeM, Ferreira PH. Short report: intra-tester reliability of two clinical tests of transversus abdominis muscle recruitment. Physiother Res Int. 2006;11(1):48-50.

33. Figueiredo MK, Chaves Júnior IP, Figueiredo VGC, Costa LOP, Menezes LC. Estudo da confiabilidade intra e entre-examinadores da unidade de biofeedback pressórico na medida da contração do músculo transverso abdominal. Rev Bras Ciênc Mov. 2005;13(4):93-100.

34. von Garnier K, Köveker K, Rackwitz B, Kober U, Wilke S, Ewert T, et al. Reliability of a test measuring transversus abdominis muscle recruitment with a pressure biofeedback unit. Physiotherapy. 2009;95(1):8-14.

35. Lima POP, de Oliveira RR, Costa LO, Laurentino GE. Measurement properties of the pressure biofeedback unit in the evaluation of transversus abdominis muscle activity: a systematic review. Physiotherapy. 2011;97(2):100-6.

36. Lima POP, Oliveira RR, Moura Filho AG, Raposo MCF, Costa LOP, Laurentino GEC. Reproducibility of the pressure biofeedback unit in measuring transversus abdominis muscle activity in patients with chronic nonspecific low back pain. J Bodyw Mov Ther. 2012;16(2):251-7.

37. Sampaio RF, Mancini MC. Estudos de revisão sistemática: um guia para síntese criteriosa da evidência científica. Rev Bras Fisioter. 2007;11(1):83-98.

38. Hulley SB, Cumming SR, Browner WS, Grady D, Hearst N, Newman TB. Delineando a pesquisa clínica - Uma abordagem epidemiológica. $3^{\text {rd }}$ ed. Porto Alegre: Artmed; 2008.

39. van Middelkoop M, Rubinstein SM, Verhagen AP, Ostelo RW, Koes BW, van Tulder MW. Exercise therapy for chronic nonspecific low-back pain. Best Pract Res Clin Rheumatol. 2010;24(2):193-204.

40. Richardson CA, Jull GA. Muscle control-pain control. What exercises would you prescribe? Man Ther. 1995;1(1):2-10.

41. Hodges PWG, Gandevia SC, Richardson CA. Contractions of specific abdominal muscles in postural tasks are affected by respiratory maneuvers. J Appl Physiol. 1997;83(3):753-60.

42. Chanthapetch P, Kanlayanaphotporn R, Gaogasigam C, Chiradejnant A. Abdominal muscle activity during abdominal hollowing in four starting positions. Man Ther. 2009;14(6):642-6.

43. Hermens HJ, Freiks B, Disselhorst-Klug C, Rau G. Development of recommendations for SEMG sensors and sensors placement procedures. J Electromyogr Kinesiol. 2000;10(5):361-74.

44. Vasseljen 0, Fladmark AM, Westad C, Torp HG. Onset in abdominal muscles recorded simultaneously by ultrasound imaging and intramuscular electromyography. J Electromyogr Kinesiol. 2009;19(2):e23-31.

45. Yang YS, Koontz AM, Triolo RJ, Mercer JL, Boninger ML. Surface electromyography activity of trunk muscles during wheelchair propulsion. Clin Biomech (Bristol, Avon). 2006;21(10):1032-41.

46. Costa LOP, Maher CG, Latimer J. Self-report outcome measures for low back pain: searching for international cross-cultural adaptations. Spine (Phila Pa 1976). 2007;32(9):1028-37.

47. Maher CG, Latimer J, Costa LOP. The relevance of cross-cultural adaptation and clinimetrics for physical therapy instruments. Rev Bras Fisioter. 2007;11(4):245-52.

48. Costa LOP, Maher CG, Latimer J, Ferreira PH, Ferreira ML, Pozzi GC, et al. Clinimetric testing of three self-report outcome measures for low back pain patients in Brazil: which one is the best? Spine (Phila Pa 1976). 2008;33(22):2459-63.

49. Soares JF, Siqueira AL. Introdução à estatística médica. $2^{\mathrm{a}}$ ed. Belo Horizonte: Coopmed; 2002.

50. Santos C. Estatística descritiva: manual de auto-aprendizagem. 2a ed. Lisboa: Sílabo; 2007.

51. Conover WJ. Practical nonparametric statistics. $3^{\text {rd }}$ ed. New York: Wiley; 1999

52. Munro H. Statistical Methods for Health Care Research. $5^{\text {th }}$ ed. Philadelphia, PA: Lippincot Williams \& Wilkins; 2005

53. Gadotti IC, Vieira ER, Magee DJ. Importance and clarification of measurement properties in rehabilitation. Rev Bras Fisioter. 2006;10(2):137-46

54. Hodges $P$, Richardson $C$, Jull G. Evaluation of the relationship between laboratory and clinica tests of transversus abdominis function. Physiother Res Int. 1996;1(1):30-40.

55. Richardson CA, Snijders CJ. Hides JA, Damen L, Pas MS, Storm J. The relation between the transversus abdominis muscles, sacroiliac joint mechanics, and low back pain. Spine (Phila Pa 1976). 2002;27(4):399-405.

56. Falla D, Jull G, Dall'Alba P, Rainoldi A, Merletti R. An electromyographic analysis of the deep cervical flexor muscles in performance of craniocervical flexion. Phys Ther. 2003;83(10):899-906.

57. Hides JA, Richardson CA, Jull GA. Multifidus muscle recovery is not automatic after resolution of acute, first-episode low back pain. Spine (Phila Pa 1976). 1996;21(23):2763-9.

58. Jull G, Richardson C, Toppenberg R, Comerford M, Bui B. Towards a measurement of active muscle control for lumbar stabilisation. Aust J Physiother. 1993;39(3):187-93.

59. Rothstein JM. Measurement in physical therapy. New York: Churchil Livingstone; 1985.

60. Finch E, Brooks D, Stratford PW, Mayo NE. Physical rehabilitation outcome measures. $2^{\text {nd }}$ ed Hamilton, Ontario: Lippincott Williams \& Wilkins; 2002.

61. Rice DA, McNair PJ, Lewis GN. Mechanisms of quadriceps muscle weakness in knee joint osteoarthritis: the effects of prolonged vibration on torque and muscle activation in osteoarthritic and healthy control subjects. Arthritis Res Ther. 2011;1(5)3:R151.

62. Philippon MJ, Decker MJ, Giphart JE, Torry MR, Wahoff MS, LaPrade RF. Rehabilitation exercise progression for the gluteus medius muscle with consideration for iliopsoas tendinitis: an in vivo electromyography study. Am J Sports Med. 2011;39(8):1777-85

63. Distefano LJ, Blackburn JT, Marshall SW, Padua DA. Gluteal muscle activation during common therapeutic exercises. J Orthop Sports Phys Ther. 2009;39(7):532-40.

64. Fleiss J, Levin B, Paik M. Statistical methods for rates and proportions. $3^{\text {rd }}$ ed. New York: John Wiley \& Sons; 2003. 